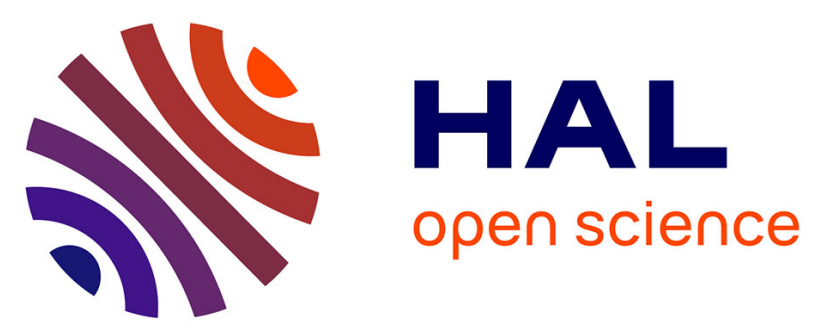

\title{
DID YOU SAY MATHS? NOT EVEN SCARED! ASSESSMENT OF THE FIRST EXERCISE PERIOD OF THE MATH PLAN OF THE ACADEMY OF MARTINIQUE \\ Manuel Philippe Emile Garcon
}

\section{To cite this version:}

Manuel Philippe Emile Garcon. DID YOU SAY MATHS? NOT EVEN SCARED! ASSESSMENT OF THE FIRST EXERCISE PERIOD OF THE MATH PLAN OF THE ACADEMY OF MARTINIQUE. 12th International Conference on Education and New Learning Technologies, Jul 2020, Online Conference, France. pp.2669-2675, 10.21125/edulearn.2020.0807 . hal-03064877

\section{HAL Id: hal-03064877 https://hal.science/hal-03064877}

Submitted on 14 Dec 2020

HAL is a multi-disciplinary open access archive for the deposit and dissemination of scientific research documents, whether they are published or not. The documents may come from teaching and research institutions in France or abroad, or from public or private research centers.
L'archive ouverte pluridisciplinaire HAL, est destinée au dépôt et à la diffusion de documents scientifiques de niveau recherche, publiés ou non, émanant des établissements d'enseignement et de recherche français ou étrangers, des laboratoires publics ou privés. 


\title{
Did you say MATHS? NOT EVEN SCARED!
}

\section{ASSESSMENT OF THE FIRST EXERCISE PERIOD OF THE MATH PLAN OF THE ACADEMY OF MARTINIQUE}

\author{
M. Garçon \\ INSPE de I'Académie de Martinique (MARTINIQUE)
}

\begin{abstract}
Numerous studies, including the well-known PISA surveys, confirm that French students present significant difficulties in mathematics (OECD, 2010, 2014 and 2015). This skills gap, as has been recognized by several observers, can have a negative impact on the human, social and economic development of a territory (CE, 2011). The problem is even more concerning in the French West Indies, where learning difficulties are linked to an educational ecosystem that is a victim of a colonial heritage and a peripheral position that has not allowed development adapted to the local specificities of the educational structures and resources available (Alì, 2017 and 2019), especially in the strategic area of STEM (science, technology, engineering, and mathematics. Roberts and de Oliveira, 2015; MENESRI, 2019).
\end{abstract}

Pending a national plan dedicated to the problems of the "overseas school", the Academies have put in place local measures to improve student performance, particularly in the so-called "fundamental" areas, including mathematics. Since 2013, the Academy of Martinique has deployed its Math Plan. One of its aims is to provide teachers in Cycles 1,2 and 3 with training and dissemination of teaching resources.

The purpose of this communication is to present an initial assessment and evaluation of the results achieved during the first period of operation of the Plan (2013-2017). The results of the first finding showed us that the difficulties of the students are not to be attributed to errors of execution but to a difficulty of understanding the initial concepts. Our questioning around the obstacles that made it difficult to develop an ecosystem positive to mathematical culture in primary school led us to develop a biannual academic training project (2015-2017) based on collective work and a collaborative type of work distribution, from design to evaluation of each activity, according to the criteria defined by Friend and Cook (2007) and professional benchmarks for national education trainers (MENESR, 2015 and 2016). We were aware of the benefits of this organizational modality (a horizontal division of work and the opportunity for all team members to participate in the conceptualization of activities) but also disadvantages in relation to a cooperative type organisation (which would explain and compartmentalize, from the outset, the distribution of tasks. See Dillenburg, 1999; Bruillard and Baron, 2009).

We therefore decided to set up tandems consisting of a first- and second-degree trainer who worked on the basis of three conditions: - complementarity of discourses (pedagogical and didactic contributions from joint cultures of both degrees);

- enrichment of proposed activities (through the use of digital tools for the creation of learning activities. See, for example, MMPDG, 2017); - explicit agreement to participate in a trial validated by the hierarchy (in order to ensure the collection of data over the long term).

We hope that this work can contribute to improving continuing training practices for first- and seconddegree teachers in the field of mathematics, motivating decision-makers to enhance collective work practices in national education (as claimed by several authors. See Marcel and al., 2007), particularly in contexts marked by strong cultural specificity, as in the "overseas" world.

Keywords: mathematics teaching, priority education, teacher training, collaborative work 


\section{INTRODUCTION}

Numerous studies, including the well-known PISA surveys, confirm that French students have significant difficulties in mathematics ([1], [2], and [3]). This skills gap, as has been recognized by several observers, can have a negative impact on the human, social and economic development of a territory ([4]). The problem is even more concerning in the French West Indies, where learning difficulties are linked to an educational ecosystem that inherits from a colonial culture. Moreover its peripheral position has not allowed a development adapted to the local specificities of the educational structures and resources available ([5] and [6]), especially in the strategic area of STEM (science, technology, engineering, and mathematics) as explained in [7] and [8] . Pending a national plan dedicated to the problems of the "overseas school", the Academies have put in place local measures to improve student performance, particularly in the so-called "fundamental" areas, including mathematics. Since 2013, the Academy of Martinique has deployed its Math Plan. One of its aims is to provide teachers in Cycles 1,2 and 3 with training and dissemination of teaching resources. The purpose of this communication is to present an initial assessment and evaluation of the results achieved during the first period of operation of the Plan (2013-2017). The results of the first finding showed us that the difficulties of the students are not to be attributed to errors of execution but to a difficulty of understanding the initial concepts. Our questioning around the obstacles that made it difficult to develop an ecosystem positive to mathematical culture in primary school led us to develop a biannual academic training project (2015-2017) based on collective work and a collaborative type of work distribution, from design to evaluation of each activity, according to the criteria defined by Friend and Cook [9] and professional benchmarks for national education trainers ([10] and [11]). We were aware of the benefits of this organizational modality (a horizontal division of work and the opportunity for all team members to participate in the conceptualization of activities) but also disadvantages in relation to a cooperative type organisation (which would explain and compartmentalize, from the outset, the distribution of tasks. See in Dillenburg ([12]), Bruillard and Baron, ([13])).

\section{METHODOLOGY}

The academy of Martinique has gradually set up a group of nine teacher trainers recruited from primary and secondary schools. An annual mission letter specifies their field of action. These teacher trainers are placed under the authority of two inspectors, academic coordinators of priority education. The staff from primary schools are departmental educational advisers in french and mathematics; those from the secondary schools are teachers who are given a nine-hour discharge to carry out their mission. These teachers work in the following subjects: mathematics, literature and PE.

We therefore decided to set up tandems consisting of a primary school trainer (Ms Carole) and a secondary school trainer (M. Garçon) who worked on the basis of three conditions

- complementarity of discourses (pedagogical and didactic contributions from joint cultures of both primary and secondary education)

- enrichment of proposed activities (through the use of digital tools for the creation of learning activities. See, for example, [14])

- explicit agreement to participate in a trial validated by the hierarchy (in order to ensure the collection of data over the long term).

As the teacher was the target audience, it was important to be able to have an objective evaluation of their training. Although off the cuff reactions (through paper assessments or by oral exchanges immediately at the end of the training) allowed us to get a first idea, they remained too subjective because they were related to emotions. We needed tools to know what the trainees understood, learnt, and would use in their next lessons on the topic. So we chose to assess the teachers in several ways: 
- exchanges before, during and after each training session. Sharing of views with the trainees were necessary before the observed class in order to discuss the material and time organization, and to explain some of our educational choices. During the class, we sometimes discussed with them the didactic variables we had chosen in order to best support the students. That was when we could bring into focus and clarify a key point of the course.

At the end of the lesson, we analyzed the details of the lesson with the trainees and we discussed possible improvements: how could they teach efficiently? The sharing of views and the analysis of professional actions brought out gestures, skills and pragmatic knowledge which could be supporteded by a didactic knowledge.

The work done then was cooperative. These exchanges were as much part of the training as of its evaluation.

- an observation grid of the lesson led by the trainees. Its purpose was to observe the difficulties and the successes encountered by the trainee teachers and to put in place the necessary means to continue their journey/training, but also to identify the needs of the students and monitor their progress. It was therefore a monitoring tool which allowed to appreciate the work of the teacher, the work of the pupils and the forms of interaction between them. This grid was designed so that the observations made could be kept on the same sheet. It was only held by the two trainers.

- an online assessment questionnaire to be completed by trainee teachers at the end of the program. We placed it at the end of our first training session. Its placement in time allowed a reliable feedback, going beyond the first feelings. It asked some essential questions about the experience of this experiment and allowed us to compare our three working hypotheses with their own perceptions.

The activities offered to trainee teachers were of three types: formative (face-to-face), consolidation (online) and analysis of professional practice in individual and group interviews. They were assessed with two objectives:

- Describe the teachers' practices through systematic observations in order to detect possible changes in professional posture;

- Know the perceptions, expectations and measure the level of satisfaction of the teachers via interviews and an online questionnaire.

\section{RESULTS}

In order to organize the results, we choose to use the evaluation model of Donald Kirkpatrick, an American researcher, who is trying to establish a culture of results in training [15].

This model revolves around four levels of impact of the training action, with no hierarchical relationship between them but each having an extension in the following level:

- Level 1: Reactions (what the learner appreciated)

- Level 2: Learning (what the learner has learned)

- Level 3: Behaviors (what has changed in the way they work the concept)

- Level 4: Results (at student level)

Teachers are the target audience of our training action. We used the written or oral answers given by the trainees during our discussions. We finally based ourselves on the notes that we ourselves took during the sessions.

\subsection{Evaluation}

\subsubsection{Level 1: Reactions (what the learner appreciated)}

Their reactions off the cuff were positive in each of the schools of the experimental panel so as to the working conditions and the experiment in itself. To the question used to assess this training: "How did 
you experience the presence of both primary and secondary school trainers during the implementation of the session?" ", one of the proposed answers was:" It was a very fruitful and appreciated presence ". We have been sufficiently receptive to their requests and been able to link everyday practices to didactic knowledge. We also perceived mutual aid and a great deal of availability among the trainees.

\subsubsection{Level 2: Learning (what the learner has learned)}

From the lessons presented, we were able to set up a dialogue on didactics and pedagogy with regard to the notions of perimeter and area. The answers to our online questionnaire were encouraging. They mainly reported on the enrichment of their basics in mathematics. One teacher used these words to mean it: "Primary and secondary school teacher trainers who are experts, bring all their knowledge in didactics of mathematics. "

\subsubsection{Level 3: Behaviors (what has changed in the way they work the concept)}

The training engineering deployed, by its innovative aspect, had lasting repercussions on the daily practice of colleagues. In fact, the activities designed by the trainers, and used in the classroom, were able to be discussed among peers and gave rise to many questions which led to enrichment, both didactic and pedagogical, of the teachers and mathematical instructors. By talking to us, they showed a willingness to distance themselves from the supports offered by the publishers, especially for the types of activities and work instructions.

The critical analysis of the tools made available to the teaching staff is an approach which seems essential to us. We had chosen to make it a working session during the national mathematics webcast day of March 22, 2017 at the ESPE: "Analysis of the contents of textbooks". The audience of primary school teachers was sensitive to this lively reflection during the workshops.

\subsubsection{Level 4: Results (at student level)}

The training program is an answer proposed by the Mathematics Mission following the analysis of the results of the students of our academy wich are generelly poor. Teachers as well as trainers wish then to improve the results of their pupils by the quality of their practice. In our case, the observation of students in class and the report of their results is convincing.

A teacher explains: "With trainers inside the classroom, students are used to having several teachers around. They are therefore asking for more explanations and this encourages their investment in the task. " The students of Cycle 3 welcomed the sessions and the organization that we proposed them, their participation was effective. For one of the teachers: "the photos of the pupils' work as well as the videos made of their oral productions value the children and motivate them even more".

Beyond this quick start to work, the teachers observed better listening to the instructions, an increase in their cognitive capacities, an adequate use of the measuring instruments and the agreed lexicon.

In addition, the teachers appreciated the demanding level of the exercises given, up to the official programs. Some new skills have emerged such as "paying attention to reading and understanding information", which may explain some success.

\subsection{Analysis and Discussion}

The choice of this training program is the result of a long reflection between trainers and referring inspectors, following numerous internal regulations. It was in a climate of confidence that the implementation was carried out. In use, the observation grid was deemed to be too long; Only one line of observation was enough, that of the teacher. The pupils' results were regularly recorded by each person who conducted the training. Video or photographic recordings were also made by the trainers during class observation. 
We will now consider the four areas of professional competence of the trainer and compare our working hypotheses, namely:

- the complementarity of the speeches for a better quality of the exchanges

- enriching the activities offered by the use of digital tools

- the possibility of follow-up in classes from elementary to middle school

\subsubsection{The complementarity of speeches for a better quality of exchanges}

We had assumed that pedagogical and didactic contributions coming from the joint cultures of the two school levels would lead the trainee teachers to a better understanding of the complex notions of perimeter and area.

We observed an added value of this complementarity of speeches and experiences in the four areas of competence of the trainer. It seems to be most visible in the design phase. Indeed, it was necessary to find an applicable and acceptable training modality for both school levels.

In addition, during the development of the sessions, the relevance of the exchanges was based on questions or experiences lived by each teacher. Sessions led by both primary and secondary school teachers gave strength, legitimacy to our common discourse.

Satisfied by this innovative animation, a trainee said: "There is an enrichment of practices, of skills to acquire".

The analysis and evaluation phase of the program was also "enriched by the culture of both primary and secondary schools". This allowed "a real sharing of skills", "a different look at the errors of the students but also the difficulties encountered by the teachers in the design of their course" and "a better harmonization practices in primary and secondary schools" according to the trainees.

In the results of our online questionnaire for teachers, it emerged that our tandem of trainers was "an example of the collaboration between primary and secondary schools, required by cycle 3".

In addition, it should be noted that the presence of the animators at our side enriched the exchanges and brought links between the teachers, the trainers and the students. Cooperative work gave meaning to the actions to be carried out, favored speaking out, and exchanges between peers were fruitful.

\subsubsection{The enrichment of the proposed activities by the use of digital tools}

We are choosen to work on the notion of perimeter and area. You should know that the work on these quantities is intimately linked to the number system. The reference tools used by the students are traditionally the graduated ruler, the square and the compass. However, in our opinion, it was necessary to build activities allowing to confront conjectures with measures. To do so the supports had to be in "real size" yet word processing software did not allow to obtain sufficient precision. We then used the richness of Photoshop software. Indeed, we had assumed that creating activities through the use of digital tools such as Photoshop software would bring clarity and precision in drawing and diagramming. Photoshop is best known as photo editing software. However, it is this tool, proposed by the educational consultant, that allowed us to develop activities without any other restriction or limitation than our creativity. The principle is that each object is placed on a layer. We can thus change the color, move at leisure, modify, play on the opacity, enlarge, reduce any object. The final document is obtained by superimposing the different layers containing the objects.

Thanks to this, we were able to make adjustments between the support we offered, the expectations of the teachers, the foreseeable difficulties of the students and our didactic variables. We have also thought out and chosen teaching materials based on the material possibilities of schools and colleges (number of photocopies, video projector, use of color). The use of digital tools offers easy manipulation, brings more clarity in the perception of figures and representations and gives meaning to our theoretical discourse.

This work on the activity materials was greatly appreciated by the teachers. One of them put it this way: "The media used are always of high quality and varied in nature. They work not only on the notions of area and perimeter but also make it possible to reinvest concepts in other fields or notions such as in space and geometry (Tangram) or in measurement of length (use of the compass to report measurements and trace the segment equal to the perimeter)." 


\subsubsection{The possibility of follow-up in classes from elementary to middle school}

We successfully conducted our experiment on the whole Cycle 3, from year 5 to Year 7, building a bridge between primary and secondary education. We are however aware of the particular work context. Indeed, the specific framework of the reinforced priority education networks favored the implementation of this experiment in cycle 3 through more time offered, the availability of trainers, but also an easy access to the schools and students. Our inter-school tandem was able to intervene with the same plan in CM1, CM2 and in $6^{\text {eme }}$ (Year 5, Year 6 and Year 7). This pedagogical vision over the whole cycle 3 allowed us to schedule maths learning throughout the cycle and not on a particular class level. This opportunity allowed us to better support the volunteer colleagues in Cycle 3.

\section{CONCLUSIONS}

Ms. Carole identifies three significant contributions in our collaborative work:

- An assessment of our own professionalism

- Added value of the professionalism of the Academic Trainer through confrontation and sharing:

$>$ didactic and institutional references;

$>$ views on pupils, teachers, teaching practices, resources such as textbooks, on the sessions observed or co-facilitated;

$>$ secondary / primary school cultures in terms of practices linked to temporality and organization: "what is gained, what is lost" for a rebalancing of continuity;

$>$ solutions to respond to the issues raised;

$>$ know-how

$>$ new ideas vectors of innovation.

- Reinforced credibility with teachers through better knowledge of the subject and joint interschool level communication. The proposed resources were co-constructed and tested in class situations. They thus brought about a consistent change in practices throughout Cycle 3.

The results obtained show us that the horizontal organization of work and the collaborative spirit in the team of trainers have a beneficial impact on teachers in training. The results also suggest that this spirit is an important lever for the motivation of teachers, especially those who are subject to the triple constraint exerted by:

- Teaching a discipline perceived as "difficult", as in the case of mathematics;

- The context, also perceived as "difficult", of priority education;

- The overseas context and the geographic isolation from the centers for the dissemination of mathematical knowledge

Currently, this work is continuing as part of the second phase of the Math Plan, the results of which will be available at the end of the fiscal year, in 2022.

We hope that this work can contribute to improving continuing training practices for first- and secondschool teachers in mathematics, motivating decision-makers to enhance collective work practices in national education (as claimed by several authors [16]), particularly in contexts marked by strong cultural specificities, as in the "overseas" world.

\section{ACKNOWLEDGEMENTS}

I want to thank Mr. Charles CHARPENTIER-TITY and Ms. Elvire HANNIBAL-CYRILLE, both academic correspondents for priority education in Martinique, for having entrusted me with this mission of academic trainer. I thank all the trainers in priority education from Martinique and especially the Mathematics pole represented by Ms. Karine Alexia and Ms. Joannie Carole. 


\section{REFERENCES}

[1] Organisation de Coopération et de Développement Économique, PISA 2009 Results: What Students Know and Can Do - Student Performance in Reading, Mathematics and Science. (Volume I). Paris: OCDE, 2010.

[2] Organisation de Coopération et de Développement Économique. Résultats du PISA 2012 : Savoirs et savoir-faire des élèves : Performance des élèves en mathématiques, en compréhension de l'écrit et en sciences (Volume I). Paris : PISA - OCDE, 2014.

[3] Organisation de Coopération et de Développement Économique. Résultats du PISA 2012. Note par pays : France. Paris : PISA - OCDE, 2015.

[4] Commission européenne L'enseignement des mathématiques en Europe : défis communs et politiques nationales. Bruxelles: Agence exécutive Éducation, Audiovisuel et Culture (EACEA P9 Eurydice) ,2011.

[5] M. Alì, «De l'apprentissage en famille à la scolarisation républicaine : deux cas d'étude en Guyane et en Polynésie française, » RITA - Revue Interdisciplinaire de Travaux sur les Amériques, 10(Juillet). Retrieved from http://www.revue-rita.com, 2017.

[6] M. Alì, «Quand l'ascenseur social tombe en panne : politiques scolaires et savoirs autochtones en Guyane et Polynésie française,» Journée d'études "Construction des savoirs scolaires: enjeux épistémologiques et politiques ». ESPE de Martinique - Centre de Recherche Interdisciplinaire en Lettres, Langues, Arts et Sciences Humaines (CRILLASH - EA4095), Université des Antilles. Fort de France, Martinique, 24 mai, 2019.

[7] Roberts, K. and de Oliveira, E. STEM education in France: Pathways and obstacles to greater participation. Dans B. Freeman, S. Marginson et R. Tytler (eds.). The age of STEM: educational policy and practice across the world in science, technology, engineering and mathematics, pp. 215-233. Abingdon, Oxon et New York, NY: Routledge, 2015.

[8] Ministère de l'éducation nationale, de l'enseignement supérieur, de la recherche et de l'innovation. Repères et références statistiques sur les enseignements, la formation et la recherche 2018. Paris: Ministère de l'éducation nationale, de l'enseignement supérieur, de la recherche et de l'innovation - Direction de l'évaluation, de la prospective et de la performance ,2019.

[9] Friend, M. and Cook, L. "Interactions: Collaboration Skills for School Professionals,". New-Jersey, US: Pearson Education, 2007.

[10] Ministère de l'Éducation Nationale de l'Enseignement et de la Recherche. Circulaire $n^{\circ}$ 2015-110 du 21-7-2015. Certificat d'aptitude aux fonctions de formateur académique. NOR: MENE1414096C - MENESR - SG - DGESCO - MAF2, 2015.

[11] Ministère de l'Éducation Nationale de l'Enseignement et de la Recherche. Circulaire $n^{\circ}$ 2016-148 du 18-10-2016. Formation initiale et continue - Missions des formateurs des premier et second degrés. NOR: MENH1605074C - MENESR - DGRH B1-3 - DGESCO- MAF2, 2016.

[12] Dillenbourg, P,"What do you mean by collaborative learning?" Dans P. Dillenbourg (ed.). Collaborative learning: cognitive and computational approaches, pp. 1-19. Oxford, Elsevier, 1999.

[13] Bruillard, E. et Baron, G.-L. Travail et apprentissage collaboratif dans l'enseignement supérieur : opinions, réalités et perspectives. Quaderni, 69 (printemps), 105-113, 2009.

[14] Mission mathématiques $1^{\text {er }}$ degré Martinique. Matrice d'apprentissage en grandeurs et mesures. Fiche de séquence. Repéré à http://site.ac-martinique.fr/pole-maths/?p=3562,2017.

[15] Kirkpatrick, D. L. Techniques for evaluating training programs. Journal of the American Society for Training and Development, 13(11), 3-9, 1959.

[16] Marcel, J., Dupriez, V., Périsset Bagnoud, D. et Tardif, M. Coordonner, collaborer, coopérer : De nouvelles pratiques enseignantes. Louvain-la-Neuve, Belgique : De Boeck Supérieur, 2007. 